\title{
Extrato de Própolis no Combate ao COVID-19: um Relato de Experiência em Nível da Atenção Básica em Saúde
}

\section{Propolis Extract in the Fight against COVID-19: an Experience Report at the Basic Health Care Level}

\author{
Leonardo Magela Lopes Matoso ${ }^{\mathrm{a}}$; Mônica Betânia Lopes Matosob \\ ${ }^{a}$ Universidade do Estado do Rio Grande do Norte. RN, Brasil. \\ bPrefeitura Municipal de Mossoró. RN, Brasil. \\ *E-mail:
}

\begin{abstract}
Resumo
Em função da alta infectividade e patogenicidade da COVID-19, buscam-se alternativas terapêticas para tratar e prevenir a doença. Entre estas se tem o extrato de própolis. Esse estudo objetiva descrever a utilização do extrato de própolis na Atenção Primária em Saúde durante pandemia da COVID-19 como método nutracêutico capaz de potencializar sistema imunológico e prevenir contra a infecção. Trata-se de estudo qualitativo, descritivo e exploratório, do tipo relato de experiência a respeito de ações e estratégias contingenciais/emergenciais adotados na APS. Para subsidiar discussão foram apreciados 59 estudos nacionais e internacionais obtidos em bases de dados científicas. Estudos defendem que o própolis possui ação antiviral, anti-inflamatória, anticancerígena, anticonceptiva, anti-HIV 1, antibactericida, bacteriostático, cicatricial, antiparasitária, imunomoduladora e anti-SARS e anti-COV-2, o que pode tornar esse produto um recurso complementar para tratamento da Síndrome da Angústia Respiratória Aguda provocada pela COVID-19. Observou-se que ao prescrever 30 gotas de extrato de própolis, duas vezes ao dia, para indivíduos com diagnóstico de COVID-19, apresentando tosse seca, febre, cansaço, dores de cabeça e perda de paladar e olfato; tem-se verificado que com três dias de uso do extrato de própolis, os sinais e sintomas têm diminuído significativamente, ao ponto de relatarem sentirem-se bem, e sem a doença. Acredita-se que extrato de própolis é eficiente contra COVID-19, podendo contribuir com desenvolvimento de novas tecnologias de tratamento em saúde ou desenvolvimento de novos agentes antivirais eficazes e seguros. Mais estudos acerca da própolis e sua ação contra COVID-19 precisam ser realizadas, entretanto, isso não diminui sua comprovação atual.
\end{abstract}

Palavras-chave: Pandemia. Nutracêuticos. Extrato de Própolis. Atenção Primária à Saúde.

\begin{abstract}
Due to the high infectivity and pathogenicity of COVID-19, therapeutic alternatives are sought to treat and prevent the disease. Among these, there is the propolis extract. This study aims to describe the use of propolis extract in Primary Health Care during the COVID-19 pandemic as a nutraceutical method capable of enhancing the immune system and preventing infection. This is a qualitative, descriptive, and exploratory studytype regarding contingency / emergency actions and strategies adopted in PHC. To support the discussion, 59 national and international studies obtained from scientific databases were evaluated. Studies argue that propolis has antiviral, anti-inflammatory, anticancer, anticonceptive, anti-HIV 1, antibacterial, bacteriostatic, healing, antiparasitic, immunomodulatory and anti-SARS and anti-VOC-2 properties, which can make this product a resource complementary treatment for the Acute Respiratory Distress Syndrome caused by COVID-19. It was observed that when prescribing 30 drops of propolis extract twice a day for individuals diagnosed with COVID-19, presenting dry cough, fever, tiredness, headaches and loss of taste and smell, it was verified that after three days using propolis extract, the signs and symptoms decreased significantly, to the point of reporting feeling well, and absence of the disease. Propolis extract is believed to be effective against COVID-19 and may contribute to the development of new health treatment technologies or the development of new effective and safe antiviral agents. Further studies on propolis and its action against COVID-19 need to be carried out, however, this does not diminish its current evidence.
\end{abstract}

Keywords: Pandemic. Nutraceuticals. Propolis Extract. Primary Health Care.

\section{Introdução}

A pandemia do Coronavírus (COVID-19) vem se espalhando pelo mundo inteiro desde o primeiro caso que aconteceu na província de Wuhan, na China em dezembro de 2019. Com 120 dias do início do primeiro surto, a doença se espalhou rapidamente por mais de 185 países, acarretando mais de 2.940.000 pessoas infectadas e mais de 203.822 mortes (HUANG et al., 2020).

Dados revelam que os Estados Unidos da América (EUA) se apresentam como epicentro da pandemia com 960.896 casos confirmados e 54.265 mortes confirmadas por COVID-19. No Brasil, o primeiro caso de COVID-19 aconteceu em 23 de janeiro de 2020 e a primeira morte ocorreu em 17 de fevereiro de 2020. Após 198 dias da primeira morte, já são mais de 3.345.240 pessoas infectadas com mais de 122.596 mortes no Brasil (SILVA et al., 2020; BRASIL, 2020).

Os coronavírus (CoVs) são da família Coronaviridae, vírus relativamente grande variando de 80 a $120 \mathrm{~nm}$ de diâmetro (ZHANG; JIANG, 2020). A membrana viral é cravejada com picos de glicoproteínas que dão aos coronavírus aparência de coroa, que contêm um genoma de RNA de sentido positivo de fita simples encapsulado dentro de um envelope de membrana (FEHR; PERLMAN, 2015). A classe de betacoronavírus inclui o vírus da Síndrome Respiratória Aguda Grave (SARS) (SARS-CoV), o vírus da Síndrome Respiratória do Oriente Médio (MERS) (MERS-CoV) e o agente causador do 
COVID-19, SARS-CoV-2 (ZHU et al., 2020).

Pesquisas apontam que o betacoronavírus codifica várias proteínas estruturais, incluindo a proteína glicosilada que funciona como um grande indutor de respostas imunes do hospedeiro, além da serina-protease produzida pela célula hospedeira (XU et al., 2020; ZHANG; JIANG, 2020; ZHU et al., 2020). Estas proteínas medeiam a invasão de células hospedeiras por SARS-CoV e SARS-CoV-2, via ligação a uma proteína receptora chamada de conversão da angiotensina enzima 2 localizada na membrana superficial do hospedeiro celular, além de várias proteínas não estruturais, incluindo polimerase de RNA dependente de RNA, protease principal coronavírus e protease do tipo papaína (TAN et al., 2020; PENG et al., 2020).

Em síntese, significa que estes vírus atacam o sistema respiratório inferior, causando infecção viral "semelhante" a uma pneumonia, mas também podem afetar o sistema gastrointestinal, coração, rim, fígado e sistema nervoso central, levando a múltipla falência de órgãos (LIU et al., 2020). O COVID-19 mostra sintomas lentamente ao longo de um período de incubação de cerca de duas semanas (14 dias), que podem perdurar até 21 dias. Durante esse período, o vírus se replica no trato respiratório superior e inferior, formando lesões leves, moderadas e grave (CHAN et al., 2020).

Estudos apontam que os sintomas gerais observados nos indivíduos infectados são febres, calafrios, tosse, anosmia, agneusia, dispneia e lesão nos pulmões (HUANG et al., 2020). No estágio avançado, os sintomas deste vírus mostram pneumonia que evolui para pneumonia grave e SARS, o que resulta na necessidade de suporte avançado de vida para sustentar os pulmões e manter homeostase do paciente (XU et al., 2020).

Suspeita-se da infecção pelo COVID-19 quando pacientes desenvolvem febre, tosse, anosmia, agneusia, mialgia e fadiga, com pneumonia intersticial bilateral diagnosticada na maioria dos pacientes (até $76 \%$ nas séries iniciais) por opacidade em vidro fosco e infiltrados irregulares no peito, podendo ser visualizado por tomografia computadorizada. Cerca de $20 \%$ dos casos pioram rapidamente com insuficiência respiratória ou SARS (PAULES; MARSTON; FAUCI, 2020). Denota-se que o SARS-CoV-2 é transmitido, predominantemente, por gotículas respiratórias, fômites (contato) e potencialmente pelas fezes.

O tratamento para COVID-19 ainda não apresenta medicamentos e vacinas específicas e comprovadamente seguras, o que existem são estratégias terapêuticas alopáticas e métodos holísticos, naturais e baseados na Medicina Tradicional Chinesa (MTC), que tem respondido significativamente a uma série de sintomatologias e servido como aporte imunoterápico e profilático.

Em função disso, a Organização Mundial de Saúde (OMS), serviços públicos de saúde e governos de todos os países decretaram estado de emergência aconselhando que pessoas e familiares realizassem práticas de higienização, além de medidas rígidas de controle sanitário de epidemias, como isolamento em suas casas e distanciamento social. Diante disso, emerge a necessidade de investimentos em descobertas de fármacos, vacinas e estratégias terapêuticas para tratamento ou profilaxia do COVID-19.

Sendo assim, uma gama de autores e pesquisadores têm utilizado as Práticas Integrativas e Complementares em Saúde (PIC's) como estratégia terapêutica para lidar com COVID-19, entre as práticas se têm as terapias naturais, que envolvem o uso de produtos naturais, incluindo alimentos, especiarias, produtos nutracêuticos, plantas medicinais, produtos marinhos e produtos biotecnológicos.

Nessa ótica, esse artigo visou atuar com base em um produto nutracêutico, conhecido como extrato de própolis. Própolis é uma substância fabricada pelas abelhas, que colhem resinas da natureza que são modificadas pela ação das enzimas contidas em sua saliva. As abelhas utilizam a própolis como proteção física e climática para as colmeias. As propriedades físico-químicas da própolis variam de acordo com a região em que essa é produzida. Entretanto, mais de 300 compostos químicos já foram identificados na própolis de diversas regiões do mundo, em uma tentativa de se identificar substâncias com potencial terapêutico e curativo.

Imersos na Atenção Básica em Saúde (ABS) e na linha de frente, os(as) autores(as) deste relato, enquanto Profissionais da Saúde atuantes na Atenção Básica, realizaram condutas prescritas utilizando o extrato de própolis em pacientes confirmados para COVID-19 e para aqueles que quiseram potencializar o sistema imunológico.

Dessa forma, o presente trabalho prospectou artigos científicos relacionados ao extrato de própolis em bases de dados nacionais e internacionais com intuito de apresentar a comunidade científica, aos governos e sociedade, os benefícios deste produto nutracêutico para enfrentamento da COVID-19. Além de alinhar os achados do material coletado com experiências terapêuticas empíricas em nível da Atenção Básica durante a pandemia.

Perante o exposto, esse estudo se justifica pela sua importância social, cientifica e pessoal que a temática consegue transcorrer. Enquanto justificativa social se tem vivenciado uma pandemia sem precedentes, na qual urge a necessidade de abordagens terapêuticas para a população, tanto em nível profilático como terapêutico. No que tange aos aspectos científicos, pesquisas acerca do extrato de própolis e COVID-19 são incipientes e necessitam ser abordadas, em razão da situação atual e das potencialidades que a própolis pode trazer. Enquanto abordagem pessoal, como profissionais da saúde, os autores são consoantes na utilização de métodos e abordagens terapêuticas que fujam do modelo hospitalocêntrico, tecnicista e alopático, tendo em vista que visam e defendem a utilização de medidas holísticas e naturais como potencializadoras do campo físico, espiritual e 
psicológico do indivíduo, capaz de prevenir e curar processos de adoecimento.

Diante deste contexto, a responsabilidade de profissionais e pesquisadores é pensar nos caminhos de mudança em uma perspectiva ampliada de valorização da vida e combate a esta pandemia, é preciso, assim, ressignificar condutas, atos e valores. Neste processo de mudança, o saber e o fazer devem estar intimamente entrelaçados, a fim de possibilitarem novos olhares e novos dispositivos de cuidado articulados para uma atenção integral às pessoas que vivenciam a pandemia. Assim, o objetivo deste estudo foi descrever a experiência da utilização do extrato de própolis durante pandemia de COVID-19 em nível da Atenção Primária em Saúde (APS), tanto em pacientes que testaram positivo como aqueles que fazem uso do extrato como forma de potencializar o sistema imunológico.

\section{Desenvolvimento}

\subsection{Metodologia}

Trata-se de uma pesquisa aplicada, descritiva, qualitativa, na modalidade relato de experiência, na qual foram adotados documentos secundários para subsidiar na discussão e reforçar os achados empíricos observados in loco, durante pandemia de COVID-19 e atuação dos autores na Atenção Primária em Saúde (APS).

Esse relato de experiência descreve a percepção de profissionais da saúde acerca da utilização do extrato de própolis verde sob a COVID-19 em nível da APS, em uma Unidade Básica de Saúde (UBS) do município de Mossoró, no Rio Grande do Norte (RN), no período de março a agosto de 2020.

É necessário ressaltar que para o desenvolvimento dessa pesquisa, principalmente, no que tange a construção do aporte teórico, foram percorridas etapas sistemáticas com a finalidade de catalogar/apurar material científico (artigos/ dissertações/teses), que recaíssem na discussão proposta e pudessem validar e reforçar as experiências tecidas.

Nessa ode, os critérios de inclusão desse estudo foram artigos/dissertações/teses empíricos, experimentais ou quaseexperimentais, ensaios e/ou de caso controle; cujo texto fosse completo, publicados em português, inglês ou espanhol, sem limite de tempo e que abordassem a temática proposta no título do artigo/ou resumo.

A busca dos artigos ocorreu nas seguintes bases de dados, a saber: PubMed, Science Direct da Elsevier, Scientific Eletronic Library Online (SciELO), Base de Dados de Enfermagem (BDENF), Literatura Latino-Americana e do Caribe em Ciências da Saúde (Lilacs), Coleciona Sus, Medical Literature Analysis and Retrieval System Online (Medline), Litterature Scientifique en Santé (LISSa), Base de dados da Springer-Nature e American Chemical Society. Foram utilizados para auxiliar na busca os seguintes descritores: "Infecções por Coronavírus", "Nutracêuticos", "Própolis" e
“Atenção Primária à Saúde".

Para complementar a busca se optou pelo cruzamento utilizando operadores booleanos AND entre os descritores: Infecções por Coronavírus AND Própolis; Própolis AND Atenção Primária à Saúde; Própolis AND Nutracêuticos, segundo os Descritores em Ciências da Saúde (DeCS).

Salienta-se que como critérios de exclusão foram definidos editoriais; cartas; artigos de opinião, revisão, comentário, teóricos; resumos de anais; publicações duplicadas; dossiês; documentos oficiais de programas nacionais e internacionais; relatos de experiência; boletins epidemiológicos; relatórios de gestão e livros.

De posse destas inferências se partiu para captação dos artigos que subsidiaram este estudo, logo, denota-se que o corpus das inferências conceituais foi construído com 57 artigos, 01 dissertação e 01 tese. Diante do exposto, salienta-se que dos estudos selecionados se empreendeu uma avaliação crítica, que atendesse aos critérios de inclusão, observando aspectos metodológicos, convergências e/ou divergências dos resultados nos diferentes estudos, possibilitando desta maneira, análise mais robusta acerca da veracidade dos fatos. Nesse ínterim, a análise foi desenvolvida à luz do marco teórico, no qual a autenticidade de todas as referências e autores citados foram mantidos de forma rigorosa, de acordo com as normas da Associação Brasileira de Normas Técnicas (ABNT).

\subsection{Relato de Experiência}

\subsubsection{Extrato de própolis: o que é?}

A própolis é uma substância natural (nutracêutica), produzida por abelhas, através da coleta de ramos, flores, pólen, brotos e exsudatos de plantas que, acrescido de secreções salivares, ceras e produto resultante da digestão do pólen, dão origem a própolis. Esta substância resinosa é usada nas colmeias como agente esterilizante, em vedação das paredes, proteção, além de ajudar na termorregulação (LEMOS JUNIOR; LEMOS, 2013). O nome própolis é derivado do grego pro (em defesa de) e polis (cidade), e quer dizer "em defesa da cidade ou colmeia" (PEREIRA et al., 2002).

Os diferentes extratos de própolis possuem coloração (verde, vermelha e marrom) e consistência variada, dependendo da espécie de planta visitada, espécie de abelha, época de coleta e substância utilizada para sua extração (CHEN; WU; LIN, 2004). Assim, a composição química da própolis é dependente da biodiversidade de cada região visitada pelas abelhas e, geralmente, compostos biologicamente ativos como os flavonoides podem ser identificados. Normalmente, a própolis tem, em sua constituição,50-60\% de resinas e bálsamos aromáticos, $30-40 \%$ de ceras, $5-10 \%$ de óleos essenciais e 5\% de grãos de pólen. Podem estar presentes, ainda, microelementos como alumínio, cálcio, estrôncio, ferro, cobre, manganês, magnésio, silício, titânio, bromo, 
zinco e vitaminas B1, B2, B6, C e E (GOMES et al., 2016).

Dos vários compostos presentes na própolis, os flavonoides merecem atenção especial. Estes são compostos fenólicos que compreendem um amplo grupo de substâncias naturais (MANACH et al., 2004; PETER et al., 2017). A ingestão de flavonoides atua em vários processos fisiológicos, uma vez que estes compostos auxiliam na absorção e no mecanismo de ação de várias vitaminas, atuando nos processos de cicatrização como antioxidantes, além de apresentarem atividade antimicrobiana e imunomoduladora (GOMES et al., 2016). Apesar dos flavonoides serem os componentes da própolis mais extensivamente estudados, esses não são os únicos responsáveis pelas suas propriedades farmacológicas (AWALE et al., 2005; SÓ et al., 2012).

\subsubsection{Extrato de própolis: o que dizem as pesquisas?}

Estudos empíricos experimentais do tipo ensaio clínicocontrolado e randomizado evidenciaram que o extrato de própolis atua como atividade anti-inflamatória, imunomoduladora, antibactericida, anticonceptiva, antiviral, antifúngica, antiinfluenza, anti-HIV-1 e anticancerígeno (JASSO-MIRANDA et al., 2019; MOHAMED et al., 2019; BATISTA et al., 2017; ELNAKADY et al., 2017; YILDIRIM et al., 2016; SALAS et al., 2016; CONTI et al., 2015; VALENZUELA-BARRA et al., 2015; FUNAKOSHI-TAGO et al., 2015; WANG et al., 2015; GAO et al., 2014; TAKEMURA et al., 2012; RAUJO et al., 2010; SHIMIZU et al., 2008; ZHANG et al., 2003; VYNOGRAD et al., 2000; GRANGE; DAVEY, 1990; CRIŞAN et al., 1995; SZMEJA et al., 1989).

Um estudo realizado na Polônia avaliou a própolis em infecções gripais comuns em 50 pessoas durante o ano de 1987. No grupo experimental, a regressão dos sintomas ocorreu no primeiro dia de tratamento. A recuperação completa deste grupo ocorreu em um dia (5 pacientes), em dois dias (16 pacientes) e em três dias (3 pacientes). O grupo placebo teve sua plena recuperação em média 4,8 dias. No grupo própolis, os sintomas duraram 2,5 menos tempo do que no grupo controle (SZMEJA et al., 1989).

Um estudo experimental com própolis, em ágar nutriente mostrou inibição completa do crescimento de Staphylococcus aureus e epidermidis, Enterococcus spp., Corybacterium spp., Branhamella catarrhalis e Bacilus cereus. A própolis inibiu parcialmente o crescimento de Pseudomonas aeruginosa e Escherichia coli, mas não teve efeito na Klebsiella pneumoniae. Assim, verificou-se que tem efeito inibitório preferencial sobre cocos Gram-positivos (GRANGE; DAVEY, 1990).

Oliveira et al., (2006) realizaram pesquisa na Universidade Estadual de Maringá (UEM), cuja finalidade foi verificar atividade in vitro de extrato de própolis contra 67 fungos, do tipo, leveduras isoladas em onicomicose. As leveduras testadas foram Candida parapsilosis (35\%), C. tropicalis (23\%), C. albicans (13\%) e outras espécies (29\%). Evidenciou-se que própolis apresentou excelente atividade antifúngica. Frisa- se que a concentração capaz de inibir todas as leveduras foram de $5 \times 10(-2) \mathrm{mg} / \mathrm{ml}$ de flavonoides e $2 \times 10(-2) \mathrm{mg} / \mathrm{ml}$ de flavonoides, estimulando assim, a morte celular.

Com objetivo de verificar o efeito apoptótico em células de melanoma humano de seis substâncias extraídas da própolis, chamadas de propalinas A, B, C, D, E e F, Chen et al., (2004), ao induzirem seus pacientes ao tratamento com própolis durante 24 horas, perceberam alterações morfológicas celulares, tais como: condensação da cromatina do núcleo e encolhimento celular. Os autores presumiram que as alterações morfológicas celulares foram provocadas por apoptose celular mediada pelo extrato de própolis.

Pesquisa randomizada, duplo-cego e multicêntrica foi realizada na Ucrânia com 90 homens e mulheres que possuíam infecções recorrentes de herpes genital tipo II. A finalidade do estudo foi comparar a eficácia da pomada de própolis contendo naturais flavonoides com pomadas de aciclovir e placebo. Trinta indivíduos foram randomizados para cada grupo. O tratamento foi iniciado na fase de bolha. Os participantes foram examinados nos dias 3, 7 e 10 de tratamento por médicos de sete diferentes regiões. Em cada exame, as lesões foram classificadas em quatro etapas, a saber: vesiculares, ulceradas, com crosta e curadas. No $10^{-}$dia, 24 dos 30 indivíduos do grupo de própolis tinham se curado; no grupo de aciclovir, 14 de 30 pacientes e no grupo de placebo, 12 de 30 foram considerados curados $(\mathrm{P}=0,0015)$. Nesse sentido, evidenciou-se que o processo de cicatrização foi mais rápido no grupo da própolis, segundo registram Vynograd et al. (2000).

Um estudo clínico com extrato de própolis versus tinidazol foi feito com o objetivo de mostrar sua efetividade contra giardíase em 48 crianças e 90 adultos, em dois grupos selecionados aleatoriamente. A própolis foi usada com concentração menor em crianças $(10 \%)$ e os resultados mostraram cura de 52\%. Em 40 adultos (concentração a 20\%), foi obtido resultado semelhante ao do tinidazol, e quando a concentração foi elevada a $30 \%$ nos restantes 50 pacientes, houve maior efetividade $(60 \%$ de cura versus $40 \%$ com tinidazol) (MIYARES et al., 1988).

Murray, Worthington e Blinkhorn (1997) propuseram analisar os efeitos de própolis na boca na reparação de feridas cirúrgicas após sulcoplastia pela técnica Kazanjian modificada. Vinte e sete pacientes, que foram submetidos à sulcoplastia, foram divididos em três grupos: pacientes que não usam o bochecho, pacientes que usaram bochecho contendo $5 \%$ de álcool e pacientes que usaram bochecho contendo própolis em solução aquosa de 5\% de álcool. Os pacientes retornaram 7, 14, 30 e 45 dias após a cirurgia para avaliação citológica e clínica. Foi concluído que a solução para bochecho contendo própolis repara feridas cirúrgicas intrabucais e exerce efeito analgésico e anti-inflamatório pequeno; e que o veículo utilizado tem menor efeito irritante sobre as feridas cirúrgicas intrabucais.

Um estudo de caso-controle feito em pré-escolares e escolares testou o efeito da própolis na inflamação aguda e 
crônica das vias aéreas superiores, durante toda a temporada fria de 1994-1995. O monitoramento dos subgrupos investigados foi realizado por observação clínica do estado de saúde e dos sintomas característicos de doenças rinofaríngeas aguda ou crônica, bem como por exame laboratorial periódico para a detecção e caracterização viral, bacteriana ou fúngica, e do transporte de germes. A análise dos dados obtidos mostrou efeitos favoráveis desse tratamento local, com redução dos sintomas agudos ou crônicos e diminuição ou supressão da flora viral-microbiana das vias aéreas superiores (CRISAN et al., 1995).

Advoga-se que uma gama de estudos avaliou os compostos moleculares do extrato de própolis, principalmente, sob sua atividade anti-inflamatória (CONTI et al., 2015; WANG et al., 2015). Foi verificado que suas ações químico-moleculares é atribuída à presença de alguns compostos, tais como: ácido cafeico, quercetina, narigenina, flavonoides, polifenóis e o éster fenetílico do ácido cafeico (CAPE), entre outros (JASSOMIRANDA et al., 2019; GAO et al., 2014; SHIMIZU et al., 2008).

No que tange sua ação anti-inflamatória, na ótica de Mirzoeva, Grishanin e Calder (1996) esta seria resultante da inibição da liberação de prostaglandinas e de leucotrienos pelos macrófagos, mediadores do processo inflamatório. Nagaoka et al., (2003) anos depois reforçaram esta inferência ao apurarem que o extrato de própolis inibe a geração de óxido nítrico por macrófagos, o que acarreta sua atividade anti-inflamatória.

Marquele et al. (2005) aferiram que o extrato de própolis possui polifenóis, que são compostos com alta atividade antioxidante. A própolis contém uma grande variedade de outros compostos com a propriedade de sequestrar as espécies reativas de oxigênio em excesso no organismo. Esta atividade antioxidante se deve aos também flavonoides, que auxiliam na redução dos radicais livres gerados por neutrófilos. O que explicaria o mecanismo antioxidante da própolis, que resultaria em uma atividade anti-inflamatória.

Pesquisas confirmaram, ainda, que a ação da própolis sobre macrófagos resulta em aumento da capacidade fagocitária (ORSI et al., 2000), estimulação da secreção de citocinas, tais como TNF- $\alpha$, além de melhorar a ação microbicida (KHAYYAL et al., 2003; ORSI et al., 2000) e antirretroviral, como identificado na pesquisa de Costi et al. (2004).

Os autores supracitados identificaram alguns terpenos no extrato de própolis brasileiro. Ao passo que realizaram testes com a própolis em células infectadas por HIV-1 que possuíam linfócitos H9. A conclusão foi que o extrato de própolis mostrou atividade anti-HIV significativa (CE50 $<0,1 \mu \mathrm{g} / \mathrm{mL}$, TI $>186)$ e foi modificado para desenvolver agentes antiAIDS mais potentes (COSTI et al., 2004).

Foi possível notar um vasto leque de estudos que recaiam sobre as mais variadas ações e efetividade da própolis. No contexto deste estudo, a literatura relatou a presença de substâncias como flavonoides e benzofenonas no extrato de própolis. O que pode tornar esse produto um potencial recurso complementar para tratamento da SARS-COV-2, por possuir atividade citotóxica e atuar como anti-inflamatória, imunossupressora, anticarcinogênica e antiparasitária.

Petrova et al. (2010) identificaram na própolis do Quênia compostos do tipo geranil estibenos e geranil flavona como a macarangina com propriedades antibacterianas. Própolis vermelha da Nigéria demonstrou apresentar 8prenilnaringenina, 6prenilnaringenina, propolina D e macarangina com atividade antiparasitária contra Trypanossoma brucei (OMAR et al., 2016).

Um estudo de atividade anti-influenza A (H3N2) dos constituintes dos derivados sintéticos de éster de ácido cinâmico da própolis foram investigados e os resultados demonstraram que isopentil ferulato inibiu a replicação viral em estudos in vitro, além da produção de hemaglutininas (SERKEDJIEVA et al., 1992; CUETO et al., 2011).

Fernandes et al. (2015) demonstraram em pesquisa, em Santa Catarina (Brasil), que o extrato de própolis marrom pode ser utilizado em coterapia com vacinas para inibir Parvovirus canino e Coronavírus canino. $\mathrm{O}$ extrato de própolis marrom estimula a produção da resposta imune contra os antígenos estudados.

Estudo semelhante foi realizado com extrato de própolis verde de São Paulo enriquecida com Artepillina c. O extrato de própolis verde também foi utilizado em coterapia com vacinas e demonstrou ter efeito imunomodulatório aumentando os níveis de IgG em plasma canino contra o Coronavírus (FERREIRA et al., 2012).

Conti et al. (2015) evidenciaram atividade anti-inflamatória e imunomoduladora de própolis verde, própolis marrom mexicana e própolis vermelha cubana, a qual apresenta a mesma composição da própolis vermelha brasileira. No estudo se pode observar atividade anti-inflamatória e imunomoduladora para as própolis estudadas.

Vários outros efeitos biológicos da própolis são relatados, bem como propriedades hepatoprotetivas (LIN et al., 1997; SIQUEIRA et al., 2014), analgésicas (PAULINO et al., 2003; BATISTA et al., 2017), atividade estrogênica (SONG et al., 2002), efeito hipoglicêmico (MATSUI et al., 2004) e atividade regenerativa de cartilagem e ossos (CARDILE et al., 2003). Além disso, as propriedades de regeneração tecidual como cicatrização de úlceras, feridas e hepatoproteção, possivelmente, estão relacionadas com a atividade antioxidativa da própolis.

Neste contexto, observou-se uma série de implicações terapêuticas do extrato de própolis, podendo este se apresentar como tratamento em saúde ou desenvolvimento de novos agentes antivirais eficazes e seguros para combater o COVID-19. Em síntese, o Quadro 1 compila os achados teóricos levantados durante a pesquisa documental sobre o extrato de própolis e sua relação com a saúde humana e COVID-19. 
Quadro 1 - Extrato de própolis, sua atividade e mecanismo de ação com base na literatura cientifica

\begin{tabular}{|c|c|c|c|}
\hline Própolis & Atividade & Mecanismo de Ação & Referências \\
\hline $\begin{array}{l}\text { Verde } \\
\text { Brasileira }\end{array}$ & $\begin{array}{l}\text { Anti-inflamatória e } \\
\text { imunomoduladora }\end{array}$ & Estimula produção TNF- $\alpha$, IL-10 pelos monócitos humanos. & Conti et al. (2015) \\
\hline $\begin{array}{l}\text { Verde } \\
\text { Brasileira }\end{array}$ & Anti-influenza & Inibição viral. & Shimizu et al. (2008) \\
\hline $\begin{array}{l}\text { Verde } \\
\text { Brasileira }\end{array}$ & $\begin{array}{l}\text { Anti-influenza e } \\
\text { imunomoduladora }\end{array}$ & $\begin{array}{l}\text { Inibe vírus influenza e regula TNF- } \alpha \text {. É também indutor de } \\
\text { apoptose. }\end{array}$ & Takemura et al. (2012). \\
\hline $\begin{array}{l}\text { Verde } \\
\text { Brasileira }\end{array}$ & Imunomoduladora & $\begin{array}{l}\text { Aumentou a fagocitose, produção de anticorpos contra } \\
\text { eritrócitos de ovelha. }\end{array}$ & $\begin{array}{l}\text { Gao et al. (2014) } \\
\text { Orsi et al. }(2000)\end{array}$ \\
\hline $\begin{array}{l}\text { Verde } \\
\text { Brasileira }\end{array}$ & Anticonceptiva & Foi capaz de inibir em camundongos a sensação dolorosa. & Batista et al. (2017) \\
\hline $\begin{array}{l}\text { Verde } \\
\text { Brasileira }\end{array}$ & $\begin{array}{l}\text { Antibactericida e } \\
\text { bacteriostático }\end{array}$ & $\begin{array}{l}\text { Inibiu parcialmente o crescimento de Pseudomonas } \\
\text { aeruginosa e Escherichia coli }\end{array}$ & $\begin{array}{l}\text { Khayyal et al. (2003); } \\
\text { Grange; Davey (1990) }\end{array}$ \\
\hline $\begin{array}{l}\text { Verde } \\
\text { Brasileira }\end{array}$ & Imunomodulatório & $\begin{array}{l}\text { Aumentou níveis de } \mathrm{IgG} \text { em plasma canino contra o } \\
\text { Coronavírus. }\end{array}$ & Ferreira et al. (2012) \\
\hline $\begin{array}{l}\text { Verde } \\
\text { Brasileira }\end{array}$ & Antifúngica & $\begin{array}{l}\text { Ocasionou morte celular da Candida parapsilosis, C. tropicalis } \\
\text { e C. albicans. }\end{array}$ & Oliveira et al. (2006) \\
\hline $\begin{array}{l}\text { Verde } \\
\text { Brasileira }\end{array}$ & Anticancerígena & $\begin{array}{l}\text { Condensação da cromatina do núcleo e encolhimento celular } \\
\text { em } 24 \text { de uso. }\end{array}$ & Chen et al. (2004) \\
\hline $\begin{array}{l}\text { Verde } \\
\text { Brasileira }\end{array}$ & Cicatricial & O bochecho da própolis cicatrizou cirurgia de sulcoplastia. & $\begin{array}{l}\text { Murray, Worthington e } \\
\text { Blinkhorn (1997) }\end{array}$ \\
\hline Vermelha & Antiparasitário & Reduziu significativamente a giardíase em crianças. & Miyares et al. (1988) \\
\hline Vermelha & $\begin{array}{l}\text { Anti-inflamatória e } \\
\text { imunomoduladora }\end{array}$ & $\begin{array}{l}\text { Estimula produção TNF- } \alpha \text { pelos monócitos humanos e diminui } \\
\text { a produção de IL- } 10 \text {. }\end{array}$ & Conti et al. (2015) \\
\hline Vermelha & Antiparasitária & $\begin{array}{l}\text { Demonstrou atividade antiparasitária contra Trypanossoma } \\
\text { brucei. }\end{array}$ & Omar et al. (2016) \\
\hline Marrom & Antiviral & Capaz de inibir Parvovírus canino e Coronavírus canino. & Fernandes et al. (2015) \\
\hline Polonês & Antiviral & $\begin{array}{l}\text { Estudaram } 50 \text { pessoas com gripe, a própolis reduziu sintomas } \\
\text { gripais no primeiro dia. }\end{array}$ & Szmeja et al. (1989) \\
\hline Chinesa & Anti-inflamatória & Bloqueia a função de TNF- $\alpha$ B. & $\begin{array}{l}\text { Wang et al. (2015); } \\
\text { Mirzoeva et al. (1996). }\end{array}$ \\
\hline Mexicana & $\begin{array}{l}\text { Anti-inflamatória e } \\
\text { imunomoduladora }\end{array}$ & Estimula produção TNF- $\alpha$, IL-10 pelos monócitos humanos. & $\begin{array}{l}\text { Conti et al., (2015); Perote } \\
(2016) ; \text { Crisan et al., } \\
(1995)\end{array}$ \\
\hline Mexicana & $\begin{array}{l}\text { Antiviral e } \\
\text { imunomoduladora } \\
\text { contra dengue }\end{array}$ & $\begin{array}{l}\text { A quercetina e a fisetina regulam negativamente a produção de } \\
\text { citocinas pró-inflamatórias induzidas pela infecção pelo vírus } \\
\text { da Dengue. }\end{array}$ & Jasso-Miranda et al. (2019) \\
\hline Ucraniana & Cicatricial & Propriedade cicatricial em herpes genital tipo II & Vynograd et al. (2000) \\
\hline Egípcia & $\begin{array}{l}\text { Antiviral e } \\
\text { imunomoduladora }\end{array}$ & $\begin{array}{l}\text { Aumento da produção de anticorpos pelo teste da } \\
\text { hemaglutinação. }\end{array}$ & Mohamed et al. (2019) \\
\hline Canadense & Antivírus & $\begin{array}{l}\text { Inibe vírus da Herpes simples e suprime a replicação do vírus } \\
\text { da hepatite } \mathrm{C} \text { in vitro. }\end{array}$ & $\begin{array}{l}\text { Vynograd et al. (2000); } \\
\text { Zhang et al.b(2003) }\end{array}$ \\
\hline Canadense & Anti-HIV-1 & CAPE inibe atividade do HIV-1 atuando na integrase viral. & Costi et al. (2004). \\
\hline Turca & Antiviral & $\begin{array}{l}\text { Derivados do ácido cafeico são eficazes no vírus herpes } \\
\text { simplex } 1 \text { e } 2 \text {. }\end{array}$ & Yildirim et al. (2016) \\
\hline Argentina & Anti-inflamatória & $\begin{array}{l}\text { Reduz atividade da lipoxigenase, cicloxigenase e produção de } \\
\text { NO. }\end{array}$ & $\begin{array}{l}\text { Salas et al. }(2016) \\
\text { Nagaoka et al. }(2003)\end{array}$ \\
\hline Chilena & Anti-inflamatória & Diminui produção de NO. & $\begin{array}{l}\text { Valenzuela-Barra et al. } \\
\text { (2015). }\end{array}$ \\
\hline Nepalesa & Anti-inflamatória & Suprime a expressão do RNAm via IL-33. & $\begin{array}{l}\text { Funakoshi-Tago et al. } \\
(2015)\end{array}$ \\
\hline $\begin{array}{l}\text { Arábia } \\
\text { Saudita }\end{array}$ & Anticancerígena & $\begin{array}{l}\text { Células T Jurkat, pulmão A549, carcinoma hepático HepG2 e } \\
\text { carcinoma cervical SW756 com IC50 1,8-6,3 } \mu \mathrm{g} / \mathrm{mL}\end{array}$ & Elnakady et al. (2017). \\
\hline Quênia & Antibacteriano & $\begin{array}{l}\text { Compostos de geranil estibenos e geranil flavona com } \\
\text { propriedades antibacterianas. }\end{array}$ & Petrova et al. (2010) \\
\hline
\end{tabular}
Fonte: Dados da pesquisa.

\subsubsection{Extrato de própolis no combate da COVID-19: experiências na atenção básica}

O enfrentamento da pandemia de COVID-19 pelo município de Mossoró, no Rio Grande do Norte (RN), teve início na primeira quinzena do mês de março, quando a Secretaria Municipal de Saúde apresentou seu plano de contingência, com protocolos e fluxos aos profissionais de saúde da rede do município. Nesse período não havia nenhum 
registro de COVID-19 na cidade. Menos de uma semana depois, dia 21 de março, foi registrado o primeiro caso. Uma semana depois, o município registrou o início da transmissão comunitária da COVID-19 e havia 14 casos confirmados. Dessa maneira, instalou-se um comitê de enfrentamento da COVID-19 para assessorar a tomada de decisões o que determinou a suspensão das aulas nas escolas municipais e decretou fechamento do comércio.

Diante desta nova pandemia, o mundo passou a traçar medidas de enfrentamento e iniciou a corrida a fim de identificar novas terapêuticas e planejamento de uma vacina capaz de imunizar e interromper a linha de contágio propagada pela COVID-19. Paralelo a isso, o Conselho Nacional de Saúde (CNS) aprovou, no dia 22 de maio, uma recomendação para o Ministério da Saúde, Distrito Federal, Estados e Municípios acerca da inclusão das Práticas Integrativas e Complementares em Saúde (PIC's) na assistência ao tratamento para combater a COVID-19.

Nesse momento, em que não há ainda medicação para a cura, vários profissionais da saúde passaram a utilizar as práticas integrativas como forma de complementar a assistência. Entre estas práticas recai a utilização de produtos nutracêuticos, como o extrato de própolis. A própolis é um artigo comumente utilizado na UBS de atuação de um dos autores dessa pesquisa antes mesmo do início da pandemia. Suas prescrições eram atribuídas às sintomatologias das arboviroses e como modo de intensificar o sistema imunológico.

No início dos primeiros casos sintomáticos do território da UBS, protocolou-se a prescrição do extrato de própolis verde para pacientes sintomáticos para COVID-19 e para aqueles cujo diagnóstico havia confirmado a infecção por meio do teste rápido (swab) ou sorologia IGG/IGM.

Ao prescrever 30 gotas de extrato de própolis duas vezes ao dia (manhã e noite), diluída com 20ml de água e/ou suco para pacientes com quadro clínico de tosse seca, febre, cansaço, dores de cabeça, anosmia e agneusia; tem-se verificado que com três dias de uso rotineiro após início sintomatológico, esses sintomas têm diminuído significativamente, ao ponto de relatarem se sentirem bem, e sem a doença.

É necessário apontar que os meses de dezembro a março têm sido vistos no município como um período de pico sazonal das arboviroses em função da fase chuvosa. Dessa maneira, a UBS lida com muitos casos gripais, além de Dengue, Zika e Chikungunya. Portanto, uma gama de pacientes dava entrada com sintomatologia de arboviroses que se mesclavam ao quadro clínico de COVID-19. De todo modo, prescrevia-se o extrato de própolis como medida terapêutica, associado com outras condutas alopáticas.

Infere-se, também, que pacientes com sintomas brandos de COVID-19, que já faziam uso do extrato de própolis como medida paliativa há mais de um mês, utilizando-o uma vez ao dia, 30 gotas diluídas com $20 \mathrm{ml}$ de água, apresentaram sintomas leves de febre e dores de cabeça, que julgaram ser virose. Entretanto, quando testados sorologicamente, o IGG se apresentou reagente e o IGM não reagente, ou seja, pressupõem-se que o extrato de própolis utilizado profilaticamente tende a reduzir a carga viral da COVID-19, atenuando sua sintomatologia.

Acredita-se que o extrato de própolis por ter sua comprovação científica evidenciando que seus benefícios recaem para ações de ordem antiviral, anti-inflamatória, anticancerígena, anticonceptiva, anti-HIV 1, antibactericida, bacteriostático e imunomoduladora pode se tornar um recurso complementar para tratamento da Síndrome da Angústia Respiratória Aguda (SARS) provocada pela COVID-19, além de ser utilizada como terapêutica profilática.

Cabe reforçar que pesquisas experimentais apresentadas neste estudo são altamente auspiciosos para o futuro e outros estudos devem ser realizados, principalmente, porque lidar com uma problemática nunca vivenciada e sem precedentes históricos documentados. Pontifica-se ainda que pesquisas não experimentais, feitas em humanos, precisam ter continuidade e, dentro do possível, ter alta qualidade metodológica.

Sabe-se que o estudo ideal para verificar a efetividade e segurança de uma intervenção é o ensaio clínico randomizado, se possível duplo-cego. Precisa-se mensurar todos os efeitos do extrato de própolis e se tais efeitos se perdem com o uso continuado da própolis ou até mesmo com quanto tempo de uso a resposta imunológica é capaz de lidar com as doenças, em especial a COVID-19. Precisa-se saber se seus bons efeitos são dose-dependentes e se a médio e longo prazos efeitos colaterais podem aparecer. Todas essas questões e muitas outras têm que ser respondidas para que se possa usufruir sem medo dos benefícios da própolis.

Destarte, pelos estudos apresentados, os efeitos do extrato de própolis estão bem demonstrados nas infecções cutâneas, genitais e vias aéreas superiores em estudos isolados. Todavia, há necessidade de mais estudos com boa qualidade metodológica para ratificar as demais indicações e existe a necessidade de maiores investimentos dos governos e pesquisadores em centros de pesquisas bem aparelhados, capaz de consolidar uma terapêutica baseada em evidências.

\section{Conclusão}

O estudo desenvolvido sobre o extrato de própolis sugere que esse pode ser eficaz contra o COVID-19. A própolis demonstrou ação antiviral, anti-inflamatória, anticancerígena, anticonceptiva, anti-HIV 1, antibactericida, bacteriostático, cicatricial, antiparasitária, imunomoduladora e anti-SARS e anti-COV-2. Dessa maneira, acredita-se que pode servir como terapia profilática e paliativa na perspectiva de atenuar possíveis sintomas severos ou morte pela COVID-19.

$\mathrm{O}$ relato de experiência evidenciou que a utilização do extrato de própolis verde brasileiro em pacientes com diagnóstico de COVID-19 e que apresentou por cinco dias, quadro clínico de tosse seca, febre, cansaço, dores de cabeça, anosmia e agneusia, após três dias de uso de 30 gotas do extrato duas vezes ao dia (manhã e noite), diluída com $20 \mathrm{ml}$ de 
água e/ou suco, diminuiu a sintomatologia significativamente, principalmente, a sensação de sufocamento evidenciado por uma gama de pacientes, ao ponto de relatarem se sentirem bem, e sem a doença.

Denota-se que a escassez de medicamentos eficazes contra infecções virais, a crescente resistência a medicamentos antivirais aprovados que estão no mercado, juntamente com a falta de vacinas comprovadamente eficazes para o COVID-19, torna altamente desejável a busca e otimização de novos tratamentos alternativos e novos esquemas terapêuticos baseados em alimentos, chás, plantas medicinais, produtos nutracêuticos e baseados na MTC e terapias holísticas, uma vez que estes podem contribuir para o desenvolvimento de novas abordagens terapêuticas. Infere-se que mais estudos, incluindo ensaios clínicos randomizados e outras abordagens acerca da própolis e sua ação contra COVID-19 precisam ser realizadas, entretanto, isso não diminui sua comprovação atual.

\section{Referências}

AWALE, S. et al. Neoflavonoids and related constituents from nepalese propolis and their nitric oxide production inhibitory activity. J. Nat. Prod., v.68, n.6, p.858-864, 2005. doi: 10.1021/ $\mathrm{np} 050009 \mathrm{k}$

BATISTA, E.; TRINDADE, H.; BATISTA, M. Efeito antinociceptivo da própolis oriunda de duas vegetações distintas. Semina Ciênc.Biol. Saúde, v.36, n.23, p.23-30, 2015.

BRASIL. Ministério da Saúde. Painel de covid-19. Disponível em: <https://covid.saude

.gov.br/>. Acessado em: 2 jun. 2020.

CARDILE, V. et al. Effect of propolis on human cartilage and chondrocytes. Life Scie., v.73, n.8, p.1027-1035, 2003.

COSTI, R. et al. 2,6-Bis(3,4,5-trihydroxybenzylydene) derivatives of cyclohexanone: novel potent HIV-1 integrase inhibitors that prevent HIV-1 multiplication in cell-based assays. Bioorganic Med. Chem., v.12, n.8, p.199-215, 2004. doi: 10.1016/j.bmc.2003.10.005

CONTI, B. J. et al. Modulatory effects of propolis samples from Latin America (Brazil, Cuba and Mexico) on cytokine production by human monocytes. J. Pharm. Pharmacol., v.67, n.50, p.124131, 2015. doi: 10.1111/jphp.12431.

CUETO, A.P. et al. Atividade antiviral do extrato de própolis contra o calicivírus felino, adenovírus canino 2 e vírus da diarreia viral bovina. Cienc. Rural, v.41, n.10, p.1800-1806, 2011

CHAN, J.F. W. et al. Genomic characterization of the 2019 novel human-pathogenic coronavirus isolated from a patient with atypical pneumonia after visiting Wuhan. Emerg. Microbes Infect., v.9, n.1, p.221-36, 2020. doi: 10.1128/JCM.00310-20.

CHEN, C.N.; WU, C.L.; LIN, J.K. Propolin C from propolis induces apoptosis through activating caspases, Bid and cytochrome c release in human melanoma cells. Biochem. Pharmacol., v.67, p.53-66, 2004.

CHEN, C.N. et al. Comparison of radical scavenging activity, cytotoxic effects and apoptosis induction in human melanoma cells by taiwanese propolis from different sources. Evid Based Complement Alternat Med, v. 1, n. 2, p.175-185, 2004. doi: 10.1093/ecam/neh081.
CRIŞAN, I. et al. Natural propolis extract NIVCRISOL in the treatment of acute and chronic rhinopharyngitis in children. Romanian J. Virol., v. 46, n. 4, p. 115-133, 1995.

ELNAKADY, Y.A. et al. Characteristics, chemical compositions, and biological activities of propolis from Al-Bahah, Saudi Arabia. Scientific Reports, v.7, n.4, p.14-23, 2017. doi: 10.1038/ srep41453.

FEHR, A. R; PERLMAN, S. Coronaviruses: an overview of their replication and pathogenesis. Methods Mol. Biol., v.1282, n.15, p.1-23. 2015. doi: 10.1007/978-1-4939-2438-7.

FERNANDES, M.H.V. et al. Effect of water extract from brown propolis on production of ifn- $\gamma$ after immunization against canine parvovirus (CPV) and canine coronavirus (CCOV). Cienc. Anim. Bras., v.16, n.2, p.235-242, 2015. doi: 10.1590/1089$6891 \mathrm{v} 16 \mathrm{i} 223458$.

FERREIRA, L.N. et al. Effect of the ethanolic extract from green propolis on production of antibodies after immunization against canine parvovirus (CPV) and canine coronavirus (CCoV). Braz. J. Vet. Res. Anim. Sci., v. 49, n. 2, p. 116-121, 2012.

FUNAKOSHI-TAGO, M. et al. Anti-inflammatory activity of flavonoids in Nepalese propolis is attributed to inhibition of the IL-33 signaling pathway. Int. Immunopharmacol., v.25, p.189198, 2015. doi: 10.1016/j.intimp.2015.01.012

GAO, W. et al. Brazilian green propolis improves immune function in aged mice. J. Clin. Biochem. Nutr., v.55, n.13, p.7-10, 2014. doi: $10.3164 /$ jcbn.13-70.

GOMES M.F.F. et al. Atividade antibacteriana in vitro da própolis marrom. Pesq. Vet. Bras., v.36, n.4, p.279-282, 2016. doi: 10.1590/S0100-736X2016000400005

GRANGE, J. M; DAVEY, R. W. Antibacterial properties of propolis (bee glue). J. Royal Soc. Med., v. 83, n.3, p. 159-160, 1990.

HUANG, C. et al. Clinical features of patients infected with 2019 novel coronavirus in Wuhan, China. Lancet, v.395, n.102, p.497506, 2020. doi: 10.1016/S0140-6736(20)30183-5

JASSO-MIRANDA, C. et al. Antiviral and immunomodulatory effects of polyphenols on macrophages infected with dengue virus serotypes 2 and 3 enhanced or not with antibodies. Infection Drug Resistance, v.12, n.10, p.1833-1852, 2019. doi: 10.2147/ IDR.S210890

LEMOS JUNIOR, H. P.; LEMOS, A. L. A. Própolis. Nutrologia, v.18, n.1, p.24-26, 2013.

KHAYYAL, M.T. et al. A clinical pharmacological study of the potential beneficial effects of a propolis food product as an adjuvant in asthmatic patients. Fundam. Clin. Pharmacol. v.17, p.93-102, 2003.

LIN, S. C. et al., The influence of propolis ethanol extract on liver microsomal enzymes and glutathione after chronic alcohol administration. Am. J. Chinese Med., v.27, n.20, p.83-93, 1997

LIU, J. et al. Longitudinal characteristics of lymphocyte responses and cytokine profiles in the peripheral blood of SARS-CoV-2 infected patients. MedRxiv, 2020. doi: https://doi. org/10.1101/2020.02.16.20023671

MANACH, C. et al. Polyphenols: food sources and bioavailability. Am. J. Clin. Nutr., v.79, n.5, p.727-747, 2004.

MARQUELE, F.D. et al., Assessment of the antioxidant activities of Brazilian extracts of propolis alone and in topical pharmaceutical formulations. J. Pharm. Biomedical Anal., v.39, n.4, p.455-462, 2005. doi: 10.1016/j.jpba.2005.04.004

MATSUCHITA, H.L.P; MATSUCHITA, A.S.P. Uso da própolis 
na prevenção e tratamento da acne vulgar. Uniciencias, v.18, n.1, p.30-41, 2014. doi: 10.17921/1415-5141.2014v18n1p\%25p

MATSUI, T. et al. Strong antihyperglycemic effects of watersoluble fraction of Brazilian propolis and its bioactive constituent, 3,4,5-tri-o-caffeoylquinic acid. Biol. Pharm. Bull., v.27, n.11, p.1797-1803, 2004.

MIYARES, C. et al. Ensayo terapéutico con um preparado a base de propoleo propolisina en la giardiasis del humano. Acta Gastroenterol Latinoam, v.18, n.3, p.195-201, 1988.

MIRZOEVA, O.K; GRISHANIN, R. N; CALDER, P. C. Antimicrobial action of propolis and some of its components: the effects on growth, membrane potential and motility of bacteria. Microbiol Res., v.152, n.12, p.239-46, 1997.

MOHAMED, N.E. et al. Immunomodulation of broiler chicks to live NDV vaccine by natural supplements. Benha Vet. Med. J., v.36, n.2, p.90-99, 2019.

MURRAY, M.C; WORTHINGTON, H.V; BLINKHORN, A.S. A study to investigate the effect of a propolis-containing mouthrinse on the inhibition of de novo plaque formation. J. Clin. Periodontol., v.24, n.11, p.796-789, 1997.

NAGAOKA, T. et al. Caffeic acid phenethyl ester (cape) analogues: potent nitric oxide inhibitors from the netherlands propolis. Biol. Pharm. Bull., v.26, p.487-491, 2003.

OLIVEIRA, A.C. et al., Antifungal activity of propolis extract against yeasts isolated from onychomycosis lesions. Mem. Inst. Oswaldo Cruz, v.101, n.5, p.493-497, 2006.

OMAR, R. M. K. et al. Chemical characterisation of Nigerian red propolis its biological activity against Trypanosoma brucei. Phytochem Anal, v.27, p.107-115, 2016. doi: 10.1002/pca.2605

ORSI, R.O. et al. Immunomodulatory action of propolis on macrophage activation. J. Venomous Anim. Toxins, v. 6, n. 4, p. 205-219, 2000.

PAULINO, N. et al. Bulgarian propolis induces analgesic and anti-inflammatory effects in mice and inhibits in vitro contraction of airway smooth muscle. J. Pharm. Scie., v.93, n.3, p.307-313, 2003.

PAULES, C.I; MARSTON, H.D; FAUCI, A.S. Coronavirus infection more than just the common cold. J. Am. Med. Assoc., v. 323, n.8, p.707-708, 2020.

PENG, X. et al. Transmission routes of n2019-nCoV and controls in dental practice. Int. J. Oral Scie., v.12, n.1, p.9-15, 2020. doi: 10.1038/s41368-020-0075-9

PEROTE, L.C.C.C. Influência de soluções de clorexidina e de própolis e da simulação de pressão pulpar na resistência de união dentinária. São José dos Campos: UNESP, 2016.

PETER, C.M. et al. Atividade antiviral e virucida de extratos hidroalcoólicos de própolis marrom, verde e de abelhas Jataí (Tetragonisca angustula) frente ao herpersvírus bovino tipo 1 (BoHV-1) e ao vírus da diarreia viral bovina (BVDV). Pesq. Vet. Bras., v.37, n.7, p.667-675, 2017. doi: 10.1590/s0100$736 \times 2017000700003$

PETROVA, A. et al. New biologically active compounds from Kenyan propolis. Fitoterapia, v.81, n.6, p.509-514, 2010.

PEREIRA, A. S. et al. Própolis: 100 anos de pesquisa e suas perspectivas futuras. Quím. Nova, v.25, n.2, p.321-326, 2002.

RAUJO, M.J.A.M. et al. Efeito do tratamento com própolis de Scaptotrigona aff. postica sobre o desenvolvimento do tumor de Ehrlich em camundongos. Rev. Bras. Farm., v.20, n.4, p.580-587, 2010.
SALAS, A.L. et al. Biological activities of polyphenols-enriched propolis from Argentina arid regions. Phytomedicine, v.23, n.10, p.27-31, 2016. doi: 10.1016/j.phymed.2015.11.007

SERKEDJIEVA, J. et al. Anti-influenza vírus effect of some propolis constituintes and their analogues (Ester of substituted cinnamic acid). J. Nat. Products, v. 55, n.3, p.294-297, 1992.

SILVA, A. et al. Avaliação in vitro da atividade antimicrobiana de extrato alcoólico de própolis comparado à solução de clorexidina 0, 12\%. J. Health Scie., v.19 n.2, p.30-34, 2017. doi: 10.17921/2447-8938.2017v19n2p95-97

SILVA, S. Atividade leishmanicida de extrato hidroalcoólico de própolis brasileira em Leishmania amazonensis. Semina Ciênc. Biol. Saúde, v.36, n.24, p.40-47, 2015.

SILVA, F.R.G. et al. Phytochemical screening and in vitro antibacterial, antifungal, antioxidant and antitumor activities of the red propolis Alagoas. Braz. J. Biol., v.79, n.3, p.452-459, 2019. doi: 10.1590/1519-6984.182959

SIQUEIRA, A.L. et al. Estudo da ação antibacteriana do extrato hidroalcoólico de própolis vermelha sobre Enterococcus faecalis. Rev. Odontol., v.43, n.6, p.359-366, 2014. doi: $10.1590 / 1807-2577.1005$

SÓ, M. et al. Atividade antimicrobiana in vitro de uma suspensão de própolis frente ao Enterococcus faecalis. Rev. Fac. Odontol., v.16, n.3, p.12-30, 2012.

SONG, Y.S. et al. Estrogenic effects of ethanol and ether extracts of propolis. J. Ethnopharmacol., v. 82, n. 3, p.89-95, 2002.

SHIMIZU, T. et al. Anti-influenza virus activity of propolis in vitro and its efficacy against influenza infection in mice. Antiviral Chem. Chemother, v.19, n.11, p.7-13, 2008. doi: 10.1177/095632020801900102

STEFANELLO, R.; HERMANN, C. S. F.; DIAS, C. G. Efeitos do extrato de própolis e do óleo de melaleuca na formação do biofilme e na desmineralização dental: estudo in situ. Rev. Fac. Odontol., v.22, n.1, 28 2017. doi: 10.5335/rfo.v22i1.6588

SZMEJA, Z. et al. Therapeutic value of flavonoids in Rhinovirus infections. Otolaryngol Pol, v.43, n.3, p.180-184, 1989.

TAKEMURA, T. et al. 3,4-Dicaffeoylquinic acid, a major constituent of brazilian propolis, increases TRAIL expression and extends the lifetimes of mice infected with the influenza A Virus. Evid. Based Complement. Alternative Med., v.39. n.25, p.13-20, 2012.

TAN, W.J. et al. A novel coronavirus genome identified in a cluster of pneumonia cases - Wuhan, China 2019-2020. China CDC Weekly, v.2, n.1, p.61-62, 2020. doi: 10.46234/ccdew2020.017

WANG, K. et al. Polyphenol-rich propolis extracts from China and Brazil exert anti-inflammatory effects by modulating ubiquitination of TRAF6 during the activation of NF-B. $J$. Functional Foods, v.19, p.464-478, 2015. doi: 10.1016/j. jff.2015.09.009

VALENZUELA-BARRA, G. et al. Anti-inflammatory activity and phenolic profile of propolis from two locations in Region Metropolitana de Santiago, Chile. J. Ethnopharmacol., v.168, n.151, p.37-44, 2015. doi: 10.1016/j.jep.2015.03.050

VYNOGRAD, N.; VYNOGRAD, I.; SOSNOWSKI, Z. A comparative multi-centre study of the efficacy of propolis, acyclovir and placebo in the treatment of genital herpes (HSV). Phytomedicine, v.7, n.5, p.1-6, 2000.

$\mathrm{XU}, \mathrm{H}$. et al. High expression of ACE2 receptor of 2019-nCoV on the epithelial cells of oral mucosa. Int. J. Oral Scie., v.12, n.1, p.1-8, 2020. doi: 10.1038/s41368-020-0074-x 
ZHANG, D-H. et al. Molecular basis for treating covid-19 with official chinese herbal formula LCTE. Pharmacodynamics, v.70, n.40, p.40-55, 2020. doi: 10.21203/rs.3.rs-20828/v1

ZHANG, W.; JIANG, X. Measures and suggestions for the prevention and control of the novel Coronavírus in dental institutions. Frontiers Oral Maxillofacial Med., v.2, n.4, p.1-15, 2020. doi: 10.21037

ZHU, N. et al. A novel coronavirus from patients with pneumonia in China, 2019. New England J. Med., v.38, n.2, p.727-33, 2020. doi: 10.1056/NEJMoa2001017

YILDIRIM, A. et al. Antiviral activity of hatay propolis against replication of herpes simplex virus type 1 and type 2. Med. Scie. Monitor, v.22, n.11, p.422-430, 2016. doi: 10.12659/ MSM.897282

YNOGRAD, N.; VYNOGRAD, I.; SOSNOWSKI, Z. A comparative multi-centre study of the efficacy of propolis, acyclovir and placebo in the treatment of genital herpes (HSV). Phytomedicine, v.7, n.1, p.1-6, 2000. 